\title{
Compreendendo a Comunidade do Guajuvira, em Araucária, Paraná (PR), Brasil e sua interação com o turismo, sob uma perspectiva cultural
}

\author{
Understanding the Guajuvira Community in Araucária, Paraná (PR), Brazil, and \\ its interaction with tourism, under a cultural perspective
}

\author{
Letícia Bartoszeck Nitsche (NITSCHE, L. B.)*
}

\begin{abstract}
RESUMO - A presente pesquisa busca na Geografia Cultural, concepções para compreender o turismo sob uma perspectiva mais humana, tendo como campo de estudo o itinerário turístico 'Caminhos de Guajuvira', em Araucária, Paraná (PR), Brasil. O artigo tem como objetivo apresentar a abordagem da geografia cultural que evidencia a relação do homem com o espaço vivido e privilegia a compreensão do mesmo enquanto membro de uma comunidade, visando obter contribuições para ações de planejamento e gestão do turismo em pequenas comunidades. A metodologia contou com pesquisas bibliográficas, documentais, entrevistas e observação pessoal direta na área de estudo. Como resultado, destaca-se a concepção de espaço vivido que vem a se aliar ao princípio de procurar entender a dinâmica da vida de pequenas comunidades.
\end{abstract}

Palavras-chave: Espaço vivido; Comunidade; Itinerário turístico.

ABSTRACT - This research seeks in the Cultural Geography, concepts to understand the tourism under a more human perspective, having as the study field the tour itinerary 'Guajuvira Paths', in Araucária, Paraná (PR), Brasil. The article aims to present the cultural geography approach that reflects man's relationship with the lived space and it privileges the comprehension of that one as a member of a community in order to obtain contributions for planning and managing tourism actions in small communities. The methodology works with literature researches, documents, interviews and direct personal observation in the study area. As a result, it highlights the conception of lived space which allies to the principle of seeking to understand the dynamics of life in small communities.

Key words: Lived space; Community; Tour itinerary.

\footnotetext{
* Graduação em Turismo pela Universidade Federal do Paraná (UFPR). Especialização em Planejamento e Gestão do Turismo (UFPR). Mestrado em Geografia (UFPR). Doutoranda em Geografia (UFPR). Professora do Curso de Graduação em Turismo (UFPR). Endereço: Rua Dr. Faivre, 405, $3^{\circ}$ andar. CEP: 80060-140 - Curitiba - PR (Brasil). Telefone: 41 3360-5050. Fax: 41 3360-5226. E-mail: lticia@gmail.com
} 


\section{INTRODUÇÃO}

O surgimento de segmentos de turismo que fogem aos padrões convencionais como aqueles que levam pequenos grupos de turistas para conhecerem áreas rurais e a vida pitoresca dos moradores locais, chama a atenção para a necessidade de se conhecer melhor a dinâmica das comunidades envolvidas.

O presente trabalho busca uma abordagem mais humana para o turismo por meio da geografia cultural, a qual ultrapassa o foco exclusivo nos fatos e artefatos de uma sociedade e avança para o significado que as pessoas atribuem a eles e ao espaço assim formado por estas relações imbricadas.

Desta maneira, o turismo visto como uma atividade realizada 'por' e 'para' pessoas, também está inserido neste espaço cheio de significados, que pode ser lido pela perspectiva cultural, ainda mais quando o principal atrativo turístico é a própria cultura local, como é o caso do itinerário turístico Caminhos de Guajuvira, em Araucária (Paraná, Brasil), apresentado neste trabalho.

Tendo como campo de observações a comunidade abrangida por este itinerário, o objetivo do presente artigo é discutir uma abordagem da geografia cultural, a qual evidencia a relação do homem com o espaço vivido e privilegia a compreensão do mesmo enquanto membro de uma comunidade, visando obter contribuições para ações de planejamento e gestão do turismo em pequenas comunidades.

A comunidade em questão foi escolhida por ser representativa de muitos outros casos em que o turismo vem se desenvolvendo no meio rural, onde o atrativo principal se baseia nos aspectos produtivos e culturais das famílias, as quais passam por transformações advindas do turismo e de outros fenômenos, incidindo no seu espaço de vivência.

Neste contexto, propõe-se uma inversão do foco de análise do 'local que deve servir ao turismo' para 'o local onde vivem pessoas' antes de se pensar em qualquer atividade turística.

A Geografia Cultural oferece bases sólidas para a investigação se enveredar por este caminho, pois ajuda a compreender os lugares a partir do sentido que as pessoas dão a eles. Paul Claval julga necessário partir dos indivíduos que compõem os lugares 
"e de suas experiências, compreendendo o sentido que as pessoas dão à existência" (CLAVAL, 2002, p. 37).

Seguindo estes princípios, a metodologia da pesquisa foi orientada por uma abordagem qualitativa que combinou alguns procedimentos de investigação. Dentre eles, a pesquisa bibliográfica com autores da Geografia Cultural contribuiu para estruturar um corpo teórico, enquanto as fontes bibliográficas e documentais sobre o município de Araucária foram essenciais para a caracterização da área de estudo. A coleta de dados também contou com entrevistas realizadas com representantes da administração pública municipal ${ }^{1}$, trazendo mais informações sobre a área de estudo e auxiliando no direcionamento da pesquisa.

Por sua vez, uma investigação que visou compreender as características da comunidade em questão e sua relação com o turismo teve início a partir de uma aproximação maior da pesquisadora com o lugar. Para tal, foram realizadas visitas à área de estudo no ano de 2010 até janeiro de 2011, tanto com o ônibus da Linha Turismo Rural, propiciando a interação da pesquisadora com visitantes e proprietários componentes do itinerário, quanto, visitas ao distrito, onde foram realizadas conversas com membros da comunidade e observação in loco.

Como resultado desta investigação, pretende-se demonstrar a importância de se considerar o conhecimento sobre o espaço vivido comunitário dos moradores de locais turísticos como subsídio para futuras ações que visem maior participação da comunidade, bem como, melhor aproveitamento de uma oferta turística que privilegie a cultura local.

Na primeira parte do texto, apresentam-se os conceitos de lugar, espaço vivido e comunidade, advindos do referencial teórico da geografia cultural e, inspirando-se neles, se iniciam as primeiras reflexões sobre os aspectos comunitários do Distrito de Guajuvira.

Permeada pelo construto teórico anteriormente apresentado e por um esboço sobre a constituição da comunidade em questão, a segunda parte do artigo, evidencia os aspectos turísticos da área de estudo, remetendo-se a origem do itinerário turístico e a forma de participação da comunidade.

\footnotetext{
${ }^{1}$ Diretoria de Turismo e coordenação de projetos de cultura e turismo da Secretaria Municipal de Cultura e Turismo - SMCT; coordenadoria do Museu Tinguiquera; coordenadoria do Arquivo Histórico Archelau de Almeida Torres; coordenadoria da Sub-Prefeitura de Guajuvira.
} 


\section{A GEOGRAFIA CULTURAL BALIZANDO A PESQUISA}

A presente pesquisa tem um dos seus pilares na geografia Humanista-Cultural de base fenomenológica, já que esta vertente pode contribuir para o campo de conhecimento do turismo na medida em que procura desvendar e compreender a visão de mundo das pessoas, considerando as subjetividades, a dimensão psicológica e mental da cultura, as percepções, a experiência, a intuição, a imaginação e os sentimentos das pessoas como sujeitos.

Sobre a fenomenologia, é possível assimilar que o "método fenomenológico se mostra eficaz pela sua capacidade de remontar até as origens dos fenômenos e, portanto, não só descrevê-los na sua manifestação exterior, mas também evidenciar as fontes que os produziram" (BELLO, 1998, p. 12), considerando o ser humano como produtor destes fenômenos.

O outro pilar de sustentação teórica desta pesquisa está na geografia cultural de Paul Claval (2001; 2002), que possui uma visão integradora sobre a área e desenvolve suas idéias alinhadas à instituição das sociedades sob o viés da cultura, trazendo a discussão para a problemática do mundo atual.

Claval se aproxima das realidades vividas pelas pessoas ao defender este enfoque cultural que nas suas palavras é "fundamental para entender a ressurreição dos lugares, as transformações dos territórios e os problemas de identidades nas sociedades multiculturais de um mundo globalizado." (CLAVAL, 2002, p. 40).

\subsection{OS CONCEITOS DE LUGAR E ESPAÇO VIVIDO}

Na linha humanista, o geógrafo chinês Yi-Fu Tuan, comenta sobre a relação do homem com os lugares, dando suporte para os estudos de percepção ambiental. O autor chama a atenção para o sentimento de afeição que une as pessoas aos lugares, designado topofilia (TUAN, 1980).

Em oposição ao sentimento de afeição, Tuan também define a 'topofobia' como um sentimento de rejeição e desconforto do homem em relação aos lugares, tema amplamente desenvolvido em sua obra 'Paisagens do Medo', publicada em português em 2005. 
Para Tuan, a idéia de lugar está atrelada ao que é conhecido e transmite segurança, diferenciando-se do espaço, ligado a um conceito mais abstrato, ou seja, o "que começa como espaço indiferenciado transforma-se em lugar à medida que o conhecemos melhor e o dotamos de valor" (TUAN, 1983, p. 6).

A perspectiva de Tuan vai além dos mecanismos biológicos dos sentidos, pois envolve a cultura dos diferentes grupos humanos, incluenciando na sua percepção, valores e atitudes em relação ao ambiente.

No caso da comunidade de Guajuvira, é preciso identificar qual a relação que se estabelece entre os moradores e o lugar, levando a pesquisadora a procurar entender como se caracteriza este espaço de vivência dos moradores locais.

Retomando referenciais da geografia sobre o termo espaço vivido, ressalta-se aqui o conceito advindo das suas raízes francesa de espace vécu (espaço vivido) e fenomenológica de mundo vivido.

Ao tratar sobre mundo vivido e espaço vivido, alguns autores são claramente adeptos da Geografia Humanista fenomenológica, com destaque para Eduard Relph (1979), David Lowenthal (1982), Yi-Fu Tuan (1980; 1983), Anne Buttimer (1982), ao passo que outros seguem independentemente a linha francesa do espaço vivido (espace vécu) sem menção da fenomenologia.

Para Relph (1979, p. 3), mundo vivido é "aquele mundo de ambiguidades, comprometimentos e significados" onde os indivíduos estão inextricavelmente envolvidos em suas vidas diárias, mas o qual é tomado por muito certo. Na mesma obra, o autor (p. 6) chama a atenção para um mundo vivido cultural, onde se passa a maior parte da vida diária e está cheio de significados, como as ruas, os edifícios, as paisagens.

Já que "apesar de vivermos nele, o mundo vivido não é absolutamente óbvio, e os seus significados não se apresentam por si mesmos" (RELPH, 1979, p. 4) para desvendá-los sem destruir a complexidade dos seus significados, Relph defende o método fenomenológico como a melhor opção, pois este varia de acordo com a situação estudada, já que se trata do que é experienciado no mundo-vivido e cada vivência é diferente da outra.

Anne Buttimer (1982, p. 172), defensora da perspectiva humanista para a geografia, explica que o mundo vivido não é um mundo constituído apenas por fatos e negócios "mas um mundo de valores, de bens, um mundo prático. Está ancorado num 
passado e direcionado para um futuro; é um horizonte compartilhado, embora cada indivíduo possa construí-lo de um modo singularmente pessoal".

Kozel Teixeira (2001, p. 146) expõe que "somente uma leitura interiorizada do vivido humano pode nos permitir compreender os homens e conseqüentemente a sua organização espacial". Esta autora, na mesma obra (p. 146), baseia-se em Husserl ${ }^{2}$ para entender o conceito de mundo vivido como o "conjunto de coisas, valores, bens e mitos inerentes a um mundo subjetivo", sendo construído pela troca de significações, considerando o fato cultural como portador de sentido e gerador de significados.

Na corrente francesa do espace vécu ou espaço vivido, Gomes (2007), Claval (2002), entre outros autores, citam Armand Frémont ${ }^{3}$. Com base neste último autor, Gomes (2007, p. 319) entende que o "espaço vivido deve, portanto, ser compreendido como um espaço de vida, construído e representado pelos atores sociais que circulam neste espaço".

Frémont apud Claval (2002, p. 21) ${ }^{4}$ discute o espaço vivido atrelado ao conceito de região, expondo que a região enquanto espaço vivido precisa ser "vista, percebida, sentida, amada ou rejeitada, modelada pelos homens [...]”, ou seja, deve ser captada pela visão dos homens.

Assim, uma ciência preocupada com o espaço vivido das pessoas tende a colocar o homem no centro das pesquisas, procurando entender a sua visão sobre o mundo através da relação que estabelece com o seu espaço de vivência, onde se inclui o conceito de lugar, repleto de significados, incluindo os sentimentos topofílicos ou topofóbicos.

Admite-se, sobretudo, que o espaço vivido não é uma construção exclusivamente individual, mas o coletivo influencia neste processo, uma vez que as pessoas possuem laços de convivência com as outras e constituem uma vida em comunidade. Este é o próximo ponto a ser debatido: a comunidade.

\footnotetext{
${ }^{2}$ HUSSERL, E. A idéia da fenomenologia. Lisboa, Portugal: Edições 70, 2000. (Escritos de Husserl de 1907).

${ }^{3}$ Em referência a sua obra La région, espace vécu, publicada em 1976.

${ }^{4}$ FRÉMONT, A. La région, espace vécu. Paris: PUF, 1999. (Reedição da obra de 1976).
} 


\subsection{COMPREENDENDO A COMUNIDADE}

O termo 'comunidade', é muitas vezes utilizado sem distinção do termo 'sociedade'. É consenso entre vários autores (ALBUQUERQUE, 1999, p. 50; BAUMAN, 2003, p. 15; CLAVAL, 2001, p. 114;) que esta discussão ocorre há mais de um século e que a sistematização destes termos tem origem nos trabalhos do sociólogo Ferdinand Tönnies ${ }^{5}$, a partir de Gemeinschaft para designar comunidade e Gesellschaft para sociedade.

Segundo Albuquerque (1999, p. 50) “[...] enquanto instrumento de análise do real, o par comunidade-sociedade indica configurações sociais contrastantes, tais como o arcaico e o moderno, o afetivo e o racional, o sagrado e o secular".

Coriolano et al. (2009, p. 40) observam a perda gradativa da noção de comunidade típica de uma vida rural solidária, principalmente com a revolução industrial e aumento da população nas cidades, dando lugar à idéia de sociedade. Os autores (p. 40) esclarecem que o termo sociedade diz respeito a "outra forma de organização social, pautada no Estado, nas instituições, no controle social, no individualismo, com o domínio de tecnologias, de normas e da cultura de massa".

A discussão de Antonio Carlos Diegues (2002) sobre as 'culturas tradicionais' como um critério importante para definição de culturas ou populações, auxilia na compreensão sobre a concepção de comunidade tradicional. Para o autor (2002, p. 83), as 'culturas tradicionais':

[...] estão associadas a modos de produção pré-capitalistas, próprios de sociedades em que o trabalho ainda não se tornou mercadoria, onde há grande dependência do mercado já existente, mas não é total. Essas sociedades desenvolveram formas particulares de manejo dos recursos naturais que não visam diretamente o lucro, mas a reprodução social e cultural; como também percepções e representações em relação ao mundo natural marcadas pela idéia de associação com a natureza e dependência de seus ciclos.

Para Claval, (2001, p. 113), a comunidade "implica igualmente que os parceiros sintam-se pertencentes a um mesmo conjunto pelo qual cada um se sinta responsável e solidário", diferente da idéia de sociedade, quando "a construção social tem

\footnotetext{
${ }^{5}$ TÖNNIES, Ferdinand. Communauté et société, Paris, PUF, 1944 (1ª edição de 1887).
} 
fundamentos racionais, o interesse, a eficácia, a preocupação de assegurar a defesa e a segurança coletivas, por exemplo".

Questões culturais acabam caracterizando indivíduos dentro de um mesmo grupo, como "aqueles que compartilham dos mesmos códigos; isto facilita as alianças e as camaradagens; maneiras de se alimentar, de comer, se sentar, de vestir, ritmos, horários, etc." (CLAVAL, 2001, p. 109).

A comunidade pode ser construída a partir de várias relações, segundo Claval (2001, p. 114), por: elos de sangue que unem os membros de uma mesma família; um mesmo ideal do grupo, unido por contrato de associação ou por um projeto comum; uma mesma fé religiosa partilhada pelo grupo; a co-habitação de pequenos grupos em um mesmo lugar, formando a chamada 'comunidade de lugar'.

\begin{abstract}
A vila tradicional de uma sociedade agrária sedentária aparece como modelo da comunidade localizada. Nasce das freqüentações múltiplas impostas pela co-habitação. Os estilos de vida são semelhantes, o auxílio mútuo fácil. Os casamentos são freqüentes com as famílias das vilas vizinhas, e os casamentos entre primos são a regra. (CLAVAL, 2001, p. 116)
\end{abstract}

Na comunidade de Guajuvira, a descendência comum na etnia polonesa é uma característica essencial para formar os elos de pertencimento ao grupo comunitário. A origem polonesa advém da corrente migratória no município iniciada a partir de 1875 (ARAUCÁRIA, 1997, p. 35), sendo que mais tarde, em 1914, um grupo de imigrantes poloneses fixou residência na região do Guajuvira $^{6}$, às margens do Rio Iguaçu (ARAUCÁRIA, 2004).

A pesquisa de campo revelou que os moradores mais idosos ainda fazem uso do idioma polonês e muitos deles falam o português com sotaque, enquanto que as gerações seguintes não aprenderam o polonês.

A economia é outro aspecto que possui suas raízes na época da colonização, pois se mantém praticamente agrícola com comércio pouco desenvolvido, dependendo do centro urbano de Araucária para a maioria dos serviços e mercadorias.

A produção agrícola do distrito é diversificada, compreendendo produtos como batata-inglesa, milho, cebola, feijão, cevada, arroz, mandioca e soja, bem como ovos,

\footnotetext{
6 A criação do Distrito de Guajuvira ocorreu em 1947 (Lei Estadual no. 2 de 10/10/1947). Esta aglomeração urbana desenvolveu-se em função da implantação da estrada de ferro da Rede Viação Paraná - Santa Catarina, onde foi construída uma estação férrea em Guajuvira (PARANÁ, 1984, p. 1).
} 
galinhas e frangos de corte. A fruticultura também é expressiva: maçã, pêra, pêssego e melancia. A estrutura fundiária de até 50 ha caracteriza as pequenas propriedades que trabalham fundamentalmente com mão-de-obra familiar e um mínimo de contratação externa (PARANÁ, 1984).

Além do idioma e da economia, outros traços da cultura polonesa estão presentes no modo de vida simples, na gastronomia, na arquitetura das casas e na religiosidade desta população.

Quanto à formação das 'comunidades de lugar', apontadas por Claval (2001), foi possível observar que o papel locacional das residências do Distrito de Guajuvira distribuídas em vários núcleos é fundamental para caracterizar o pertencimento dos moradores às suas localidades ${ }^{7}$, e por conseqüência, suas comunidades. Essencialmente, a formação de cada núcleo destes se dá no entorno de uma paróquia.

É por meio dos cultos e celebrações religiosas nas paróquias que ocorrem os momentos de encontro entre as pessoas de uma localidade, conforme se confirmou nas entrevistas com moradores de Guajuvira. Quando questionados sobre quando e onde costumavam encontrar os demais membros da comunidade, as respostas apontaram os cultos semanais e os preparativos para as celebrações religiosas.

Para Claval (2001) a comunicação tem papel fundamental nestas construções culturais que vinculam os indivíduos uns aos outros por meio de uma rede complexa de relações. E, no Guajuvira detectou-se que a comunicação entre estes indivíduos ocorre habitualmente em função da instituição religiosa. Estes contatos se ampliam no caso das festas paroquiais, pois atraem visitantes das localidades vizinhas e até mesmo de outras regiões do município, promovendo uma interação entre os participantes destes eventos.

Sendo assim, percebeu-se que a fé religiosa e a co-habitação são determinantes no sentimento de pertença das pessoas em relação a sua comunidade, que normalmente se limita fisicamente a uma localidade do Distrito de Guajuvira.

O conceito de território também está implícito nesta compreensão sobre comunidade, já que de acordo com Bonnemaison (2002, p. 95), "não existe etnia ou grupo cultural que não tenha se investido física e culturalmente num território", ou como afirma Claval (2001, p. 114) que a vida em comunidade "tem necessidade de uma base territorial"'.

\footnotetext{
${ }^{7}$ Oficialmente reconhecidas pela Prefeitura Municipal de Araucária como localidades rurais, conforme constam no Mapa Temático Localidades Rurais, da Secretaria Municipal de Urbanismo, 2009.
} 
Assim os lugares, passam de um mero espaço onde se localizam as moradias para um espaço vivido por uma comunidade que estabelece um sentimento afetivo por esta terra, tanto de cada um em relação à sua propriedade, quanto do grupo tomando consciência de um patrimônio coletivo. O espaço depois de apropriado pela coletividade, detentora de uma cultura, torna-se seu território, receptáculo de uma série de marcas manifestadas pelo sentimento de posse.

Enfim, a noção de comunidade para este trabalho está ligada a existência de um grupo coeso de pessoas que estabelecem ligações de confiança mútua e de pertencimento a um território, sendo que as relações envolvidas em todo este processo concebem um espaço vivido.

\section{A PERCEPÇÃO DO TURISMO NO DISTRITO DE GUAJUVIRA}

Com base no referencial teórico e nestas últimas reflexões sobre a constituição das comunidades no Distrito de Guajuvira, o trabalho foi orientado no sentido de procurar conhecer a maneira como a comunidade participava no itinerário turístico.

\subsection{ASPECTOS GERAIS SOBRE O TURISMO NA ÁREA DE ESTUDO}

Primeiramente, apresentam-se alguns aspectos sobre a área de estudo, inserida em Araucária, município com uma população de 119.207 habitantes (IBGE, 2010) concentrados em uma área urbana de $84,00 \mathrm{Km}^{2}$, sendo que a área rural ocupa a maior parte do município, com $376,85 \mathrm{~km}^{2}$.

Araucária situa-se a $27 \mathrm{Km}$ de Curitiba e tem como principais acessos rodoviários: BR 476, BR 116, 277, BR 376, PR 423, PR 421. O Distrito de Guajuvira fica a $14 \mathrm{Km}$ do centro de Araucária e seu acesso principal é feito pela BR 476, conhecida como Rodovia do Xisto, que corta o município e é uma importante interligação com a Região Sudoeste do país.

A partir da década de 1970, com a implantação da Refinaria Presidente Getúlio Vargas - REPAR, o município vem se destacando como importante pólo industrial do Estado. Apesar de ser conhecido como um município industrial, a população de 
Araucária tem suas raízes no trabalho agrícola desenvolvido pelos imigrantes europeus que começaram a chegar por volta de 1860, com os alemães, e em 1875 com os poloneses (ARAUCÁRIA, 1997, p. 35).

A chegada dos poloneses causou transformações na região, como por exemplo, o aumento de $42 \%$ da sua população com a vinda de 270 novas famílias de imigrantes (1.116 pessoas) para a Colônia Tomás Coelho (ARAUCÁRIA, 2004, p. 44), fundada em 1876 em terras então pertencentes ao município de São José dos Pinhais (ARAUCÁRIA, 1997, p. 24).

Quanto ao turismo, o itinerário Caminhos de Guajuvira foi concebido pela Prefeitura Municipal de Araucária com a adesão dos agricultores locais, sob influência de uma política de criação de roteiros turísticos para a Região Metropolitana de Curitiba - RMC. Em Nitsche (2007, p. 20) tem-se um relato de como surgiu a concepção dos itinerários para a RMC a partir de uma proposta idealizada pelo poder público estadual:

\begin{abstract}
A formatação de roteiros turísticos com características rurais fez parte do planejamento do Anel de Turismo Rural para a RMC (PARANÁ, 1999a, 1999b ${ }^{8}$, desenvolvido em 1998 pela Coordenação da Região Metropolitana de Curitiba - COMEC, Empresa Paranaense de Assistência Técnica e Extensão Rural - Emater/PR e Serviço Social Autônomo Ecoparaná, como uma alternativa de renda e conservação ambiental para os municípios da RMC.
\end{abstract}

O itinerário turístico Caminhos de Guajuvira foi inaugurado em março de 2004, depois de uma fase de planejamento iniciada em 2001 pela Secretaria Municipal de Cultura e Turismo - SMCT, da Prefeitura Municipal de Araucária, com o apoio da Emater (ARAUCÁRIA, 2009). O projeto do itinerário se insere na proposta de desenvolvimento do Turismo Rural no município, que tem como objetivo "auxiliar o resgate cultural, possibilitar mais uma alternativa de renda ao produtor rural e proporcionar ao visitante convivência com a vida no campo" (ARAUCÁRIA, 2006, p. 2).

As ações para desenvolver o turismo rural no município contaram com cursos e reuniões sobre o tema do turismo, direcionadas para várias comunidades rurais, dentre elas a do Guajuvira. Além disso, também foram realizadas visitas turísticas

\footnotetext{
${ }^{8}$ PARANÁ. EMATER; COMEC. Turismo em áreas rurais. Agosto, 1999a e PARANÁ. EMATER; SEMAA/Colombo. Circuito italiano de turismo rural: projeto, 1999b.
} 
experimentais entre as comunidades de Araucária e excursões técnicas para outros itinerários turísticos nacionais.

Conceitualmente, este itinerário se caracteriza como uma possibilidade para percorrer um roteiro compreendido pela disposição de vários atrativos num determinado espaço, interligados por vias de acesso e facilidades de transporte, além de ações de informação e comunicação.

De acordo com Bahl (2004, p. 42), tais itinerários correspondem a "indicação de uma seqüência de atrativos existentes numa localidade e merecedores de serem visitados". Neste tipo de roteiro, o aspecto espacial em que se distribuem os atrativos é essencial no momento de definir o seu trajeto.

$\mathrm{O}$ visitante pode percorrer o itinerário tanto com o seu próprio veículo, como pelo ônibus da Linha Turismo Rural, ofertado aos sábados com o custo de R\$ 5,00. As reservas para o ônibus são realizadas via Centro de Informações Turísticas, situado as margens da BR 476 na área central de Araucária, onde o visitante recebe o material informativo do itinerário (e de outros pontos turísticos do município) contendo o nome das propriedades e atrativos, atividades, produtos oferecidos, horário de funcionamento, telefone e mapa com orientações.

Conforme se confirma no Inventário da Oferta Turística do município (ARAUCARIA, 2009), o Centro de Informações Turísticas tem sua "arquitetura inspirada nas edificações polonesas" (p. 314), em homenagem a cultura destes imigrantes.

As propriedades rurais do itinerário (QUADRO 1) têm como proposta original, propiciar o contato dos visitantes com as famílias do campo para conhecerem a sua cultura, além do comércio da sua produção de flores, frutas, produtos da horta, mel, pães, ovos, entre outros.

O itinerário tem aproximadamente 40 quilômetros de extensão e possui 10 atrativos para visitação (ARAUCÁRIA, 2009), destes, 7 localizam-se na área do Distrito de Guajuvira (QUADRO 1) e os outros 3 estão no quadro urbano do município.

Dados da SMCT (ARAUCÁRIA, 2009, p. 29) registram a demanda turística de passageiros do itinerário pelo ônibus da Linha Turismo Rural, que mantém uma média de aproximadamente 5.000 visitantes/ano para o período de 2007 a 2009. 


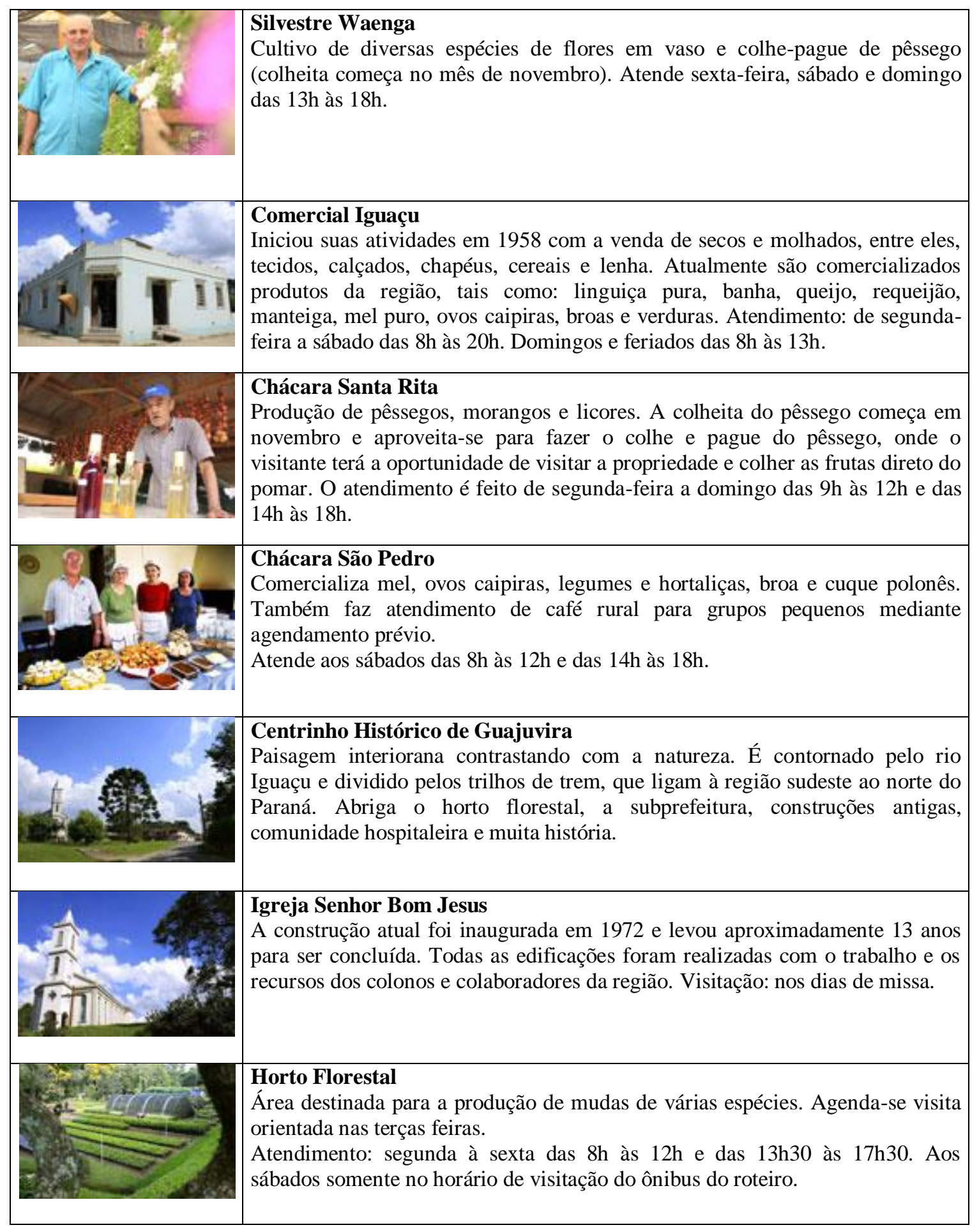

QUADRO 1 - ATRATIVOS DO ITINERÁRIO CAMINHOS DE GUAJUVIRA: ÁREA RURAL

FONTE: ARAUCÁRIA, 2009, p. 312-314.

FOTOS: ARAUCÁRIA, 2010b.

ORGANIZAÇÃO: AUTORA 


\subsection{PARTICIPAÇÃO DA COMUNIDADE EM RELAÇÃO AO ITINERÁRIO}

Durante a coleta de dados para a pesquisa junto aos representantes da SMCT em 2010, registra-se que em 2004 houve o lançamento do itinerário com 8 propriedades participando diretamente, sendo que 3 proprietários desistiram já no início do processo (2004/2005) e 1 em 2007, permanecendo 4, correspondentes às propriedades Silvestre Waenga, Comercial Iguaçu, Chácara Santa Rita e Chácara São Pedro (QUADRO 1).

Estas 4 propriedades pertencem à famílias que residem na área de abrangência do Distrito de Guajuvira, sendo a primeira delas na localidade de Camundá, a segunda na sede de Guajuvira (chamada popularmente de 'vila') e as outras duas situando-se na localidade de Campestre.

Sobre a organização interna entre estas famílias participantes, cabe ressaltar que a Secretaria de Cultura e Turismo desde o lançamento do itinerário em $2004^{9}$, vinha incentivando a formação de uma organização local, até que no final do ano de 2010 ocorreu a criação de uma associação de turismo. A mesma, composta pelos representantes de 3 das 4 famílias participantes começa então a desenvolver as suas primeiras ações, mas enfrenta o problema de não haver maior participação da comunidade.

De um modo geral, para o turismo envolvendo a população que vive do campo, é premente que as famílias locais tomem a frente da gestão dos projetos turísticos, o que não vem ocorrendo de forma efetiva no itinerário de Guajuvira.

Com base na coleta de dados em uma primeira instância de pesquisa, junto aos representantes da Prefeitura, os proprietários integrantes do itinerário e algumas pessoas da comunidade, foi possível elencar alguns fatores que estariam prejudicando uma participação mais ativa da comunidade em relação ao turismo, tais como:

- os proprietários participantes do itinerário não têm o hábito de se reunir para discutir os assuntos do turismo, salvo quando pela intermediação da SMCT, incluindo as reuniões para criação da associação;

- é escassa a comunicação entre os moradores tanto internamente em cada localidade do distrito, quanto entre elas, pois as ocasiões que propiciam o encontro se

\footnotetext{
9 Dados da entrevista pessoal realizada em 28/07/2010, com a Diretora Municipal de Turismo de Araucária.
} 
restringem aos cultos religiosos e outros eventos associados as suas paróquias, conforme relatado anteriormente.

- comodidade em relação à presença do poder público que realiza as ações;

- desconhecimento dos moradores sobre os efeitos do turismo, de um modo geral.

Diante destas constatações iniciais, considerou-se ser pertinente procurar se aprofundar em conhecer mais a dinâmica interna de cada comunidade envolvida, para compreender o porquê desta reduzida participação do conjunto de proprietários e da comunidade na condução do processo de gestão do roteiro.

Ainda, um fator a ser considerado é que o turismo não poderia ser tratado isoladamente, ou seja, está inserido em uma perspectiva social, econômica, ambiental e cultural. Também seria necessário entender a posição do turismo como apenas um dos assuntos que poderiam ser discutidos pela comunidade, dentre os demais como saúde, educação, trabalho, cultura, esporte, eventos, entretenimento, lazer, entre outros.

A maioria dos projetos turísticos em áreas rurais que contemplam várias famílias depende da coesão destas pessoas, porém, muitas vezes, esta população não se incorpora ao projeto, o qual fica sob encargo do poder público ou de outra instituição proponente. $\mathrm{O}$ poder público, mesmo quando cumpre com as suas atribuições referentes à esfera pública, pode sofrer o problema da descontinuidade política na troca de gestão, rompendo, muitas vezes, com a sua atuação no projeto.

Mesmo com a formação de organizações locais, constatada através da pesquisa de NITSCHE; NERI; BAHL (2010) sobre 3 itinerários da RMC, incluindo este de Guajuvira, observou-se que os mesmos ainda possuíam grande dependência do poder público para tomada de decisões, divulgação, comercialização, qualificação de recursos humanos, entre outras atribuições.

Esta reduzida participação da comunidade também se reflete na visão dos visitantes, ao perceberem que os aspectos produtivos e artesanais poderiam estar mais presentes no roteiro, de acordo com os dados da Pesquisa de Demanda da Linha Turismo Rural (ARAUCÁRIA, 2010a) referente ao período de 17/04 a 19/06/2010.

Nessa pesquisa, apesar de $99 \%$ do público declarar que fariam novamente o itinerário e $100 \%$ concordarem que indicariam para outras pessoas, 9 das 32 sugestões efetuadas solicitaram incluir mais propriedades no itinerário. Outros 5 visitantes 
declararam que gostariam de encontrar maior diversidade de produtos coloniais à venda, confirmando-se a necessidade de se incrementar a oferta turística do itinerário.

Supõe-se que estas características ligadas ao espaço vivido dos moradores não são percebidas com clareza pelos visitantes porque os próprios moradores não se dão conta delas e nem as reconhecem como um potencial de atração turística.

No mais, conhecer a comunidade representa para o turismo, a oportunidade de descobrir peculiaridades a serem difundidas para os visitantes, o que viria a valorizar os próprios usos, costumes e patrimônio locais.

Considera-se válido ressaltar que este não é um conhecimento sistematizado que os habitantes locais ou seus representantes tenham com clareza para passar de forma direta aos pesquisadores através de questionários fechados, mas trata-se de um conhecimento a ser descoberto por meio de métodos que considerem os sujeitos de pesquisa no contexto da sua comunidade.

\section{CONSIDERAÇÕES FINAIS}

Dentro da problemática do turismo em pequenas comunidades, o presente estudo procurou extrair da Geografia Cultural uma abordagem que evidenciasse o espaço vivido das pessoas, compreendendo-as como membros de uma comunidade.

Neste sentido, foi possível delinear pelo menos duas linhas de pensamento, que acabaram por se complementar. A primeira delas trouxe a tona o conceito de espaço vivido, advindo tanto da geografia humanista, com destaque para os estudos de percepção ambiental, quanto da corrente francesa do espace vécu, contribuindo para a compreensão dos laços de pertencimento que unem as pessoas aos seus lugares de vida (topofilia), a serem considerados no contexto do desenvolvimento do turismo.

Em virtude do espaço vivido também contemplar a esfera coletiva, é que surge a segunda linha de pensamento, abordando a idéia de comunidade, sob uma perspectiva cultural, o que foi realizado a partir de Paul Claval $(2001,2002)$ alinhado a outros autores.

Com base nestas contribuições teóricas, a pesquisa no itinerário Caminhos de Guajuvira, em Araucária (PR), Brasil, revelou vários aspectos das comunidades 
pesquisadas. Alguns deles podem servir para reforçar a identidade turística deste roteiro, como o fato das populações manterem traços da cultura dos seus colonizadores poloneses e um modo de vida tipicamente rural. E, outros, como a existência de pelo menos 3 comunidades diferentes ao longo do itinerário com pouca interação entre elas e com uma vida comunitária interna onde as atividades coletivas são restritas, vem a dificultar o conhecimento da população sobre o turismo e a própria discussão do assunto de forma espontânea dentro de cada comunidade.

Acredita-se aqui, que para qualquer projeto de turismo em comunidades rurais, onde estes moradores sejam os principais beneficiários, é necessário conhecer as suas relações com o lugar e a maneira como se inserem no contexto da comunidade, o que pode levar o pesquisador a identificar formas de incentivo para uma maior interação dos moradores neste processo de desenvolvimento turístico.

\section{REFERÊNCIAS}

ALBUQUERQUE, L. M. B de. Comunidade e Sociedade: conceito e utopia. Raízes, Ano XVIII, n. 20, novembro, 1999. p. 50-53.

ARAUCÁRIA. Prefeitura Municipal. Agricultura e Indústria: a memória do trabalho em Araucária. 2. ed., 1997.

Prefeitura Municipal. A construção de uma história: a presença étnica em Araucária (Coleção História de Araucária, v. 5), 2004.

- Prefeitura Municipal. Secretaria Municipal de Cultura e Turismo (SMCT). Programa Municipal de Turismo Rural, Araucária, 2006.

Prefeitura Municipal. Secretaria Municipal de Cultura e Turismo (SMCT). Inventário da Oferta Turística do Município de Araucária, Araucária, 2009.

Prefeitura Municipal. Secretaria Municipal de Cultura e Turismo (SMCT). Pesquisa de Demanda da Linha Turismo Rural, Araucária, 2010a.

. Prefeitura Municipal . Turismo Rural: Caminhos de Guajuvira. 7 fotografias, color. Disponível em:

$<$ http://www.araucaria.pr.gov.br/index.php?a=turismo_rural.php\&b=turismo $>$. Acesso em: 21/08/2010b. 
BAHL, M. Viagens e roteiros turísticos. Curitiba, Protexto, 2004.

BAUMAN, Z. Comunidade: a busca por segurança no mundo atual. Rio de Janeiro: Zahar, 2003.

BELLO, A. A. Culturas e religiões: uma leitura fenomenológica. Bauru: EDUSC, 1998.

BONNEMAISON, J. Viagem em torno do território. In: CORREA, R. L.; ROSENDAHL, Z. (Orgs.) Geografia Cultural: um século (3). Rio de Janeiro: EdUERJ, 2002. (Série Geografia Cultural).

BUTTIMER, A. Apreendendo o dinamismo do mundo vivido. In: CHRISTOFOLETTI, A. (Org.) As perspectivas da geografia. São Paulo: DIFEL, 1982. p. 165-193.

CLAVAL, P. A geografia cultural. 2. ed. Florianópolis: Ed. da UFSC, 2001.

A revolução pós-funcionalista e as concepções atuais da geografia. In: MENDONÇA, F.; KOZEL, S. (Orgs.) Elementos de epistemologia da geografia contemporânea. Curitiba: UFPR, 2002.

CORIOlano, L. N.; ARAúJo, A. M. M. de; VASCOnCElos, F. P. Arranjos produtivos locais do turismo comunitário: atores e cenários em mudança. Fortaleza: EdUECE, 2009.

DIEGUES, A. C. O mito moderno da natureza intocada. 3. ed. São Paulo: Hucitec, 2002.

GOMES, P. C. da C. Geografia e modernidade. 6. ed. Rio de Janeiro: Bertrand Brasil, 2007.

INSTITUTO BRASILEIRO DE GEOGRAFIA E ESTATÍSTICA (IBGE). Primeiros resultados do Censo 2010. Disponível em:

<http://www.ibge.gov.br/cidadesat/topwindow.htm?1>. Acesso em: 21/03/2011.

KOZEL TEIXEIRA, S. Das imagens às linguagens do Geográfico: Curitiba a Capital ecológica. 310 f. Tese (Doutorado em Geografia Física) - Faculdade de Filosofia, Letras e Ciências Humanas, Universidade de São Paulo (FFLCH-USP), São Paulo, 2001.

LOWENTHAL, D. Geografia, experiência e imaginação: em direção a uma epistemologia geográfica. In: CHRISTOFOLETTI, A. As perspectivas da geografia. São Paulo: Difel, 1982. p. 103-141.

NITSCHE, L. B. O significado do turismo no roteiro 'Caminhos de Guajuvira', Araucária/PR. 128 f. Dissertação (Mestrado em Geografia) - Setor de Ciências da Terra, Universidade Federal do Paraná, Curitiba, 2007. 
NITSCHE, L.; NERI, L. de F.; BAHL, M. Organizacion local de itinerarios turísticos en la Region Metropolitana de Curitiba, Paraná, Brasil. Gestion Turística. (Valdivia). [online]. jun. 2010, n. 13, p. 93-112. Disponível em:

$<$ http://mingaonline.uach.cl/scielo.php?script=sci_arttext\&pid=S0718-

64282010000100004\&lng=es\&nrm=iso >. ISSN: 0718-6428. Acesso em: 31/07/2010.

PARANÁ. Coordenação da Região Metropolitana de Curitiba (COMEC); Empresa de Assistência Técnica e Extensão Rural (EMATER/ACARPA); Prefeitura Municipal de Araucária. Plano de Desenvolvimento Comunitário Integrado de Guajuvira: Centro de Dinamização rural de Guajuvira (Documento n. 5), 1984.

RELPH, E. C. As bases fenomenológicas da Geografia. Geografia, Rio Claro, UNESP, v. 4, n. 7, abril, 1979.

Topofilia. São Paulo: DIFEL, 1980.

Espaço e Lugar. São Paulo: DIFEL, 1983.

Paisagens do medo. São Paulo: UNESP, 2005.

Recebido em: 28-02-2011.

Aprovado em: 28-03-2011. 